\title{
МУТАЦИИ ГЕНА LMNA КАК ПРИЧИНА СИНДРОМАЛЬНОЙ НИЗКОРОСЛОСТИ У ПАЦИЕНТОВ С ПРОГЕРИЕЙ ХАТЧИНСОНА-ГИЛФОРДА И АТИПИЧНЫМ ПРОГЕРОИДНЫМ СИНДРОМОМ
}

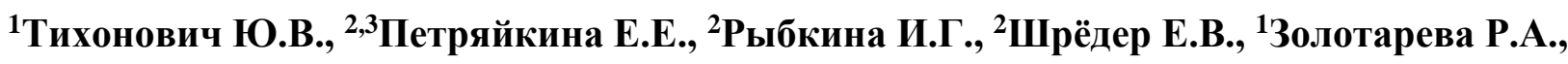 \\ ${ }^{1}$ Римская А.М., ${ }^{4}$ Тюльпаков А.Н.
}

${ }^{1}$ ФГАОУ ВО «Первый Московский государственный медицинский университет им. И.М. Сеченова (Сеченовский университет)», г. Москва

${ }^{2}$ ГБУЗ «Морозовская детская городская клиническая больница ДЗМ», г. Москва

${ }^{3}$ ФГАОУ ВО «Российский национальный исследовательский медицинский университет им. Н.И. Пирогова», г. Москва

${ }^{4}$ ФГБНУ «МГНЦ им. академика Н.П. Бочкова», г. Москва

Мутации гена LMNA (Lamin A/C) являются причиной гетерогенной группы заболеваний, включающих, в частности, прогерию Хатчинсона-Гилфорда, мандибулоакральную дисплазию, атипичный прогероидный синдром, одним из ключевых проявлений которых является прогрессирующая задержка физического развития.

Цель. Представить клинические случаи прогерии и атипичного прогероидного синдрома у пациентов с мутациями гена $L M N A$.

Материалы и методы. Клинико-лабораторное обследование пациентов проводилось в отделениях эндокринологии ФГАОУ ВО «Первый Московский государственный медицинский университет им. И.М. Сеченова (Сеченовский университет)», г. Москва и ГБУЗ «Морозовская детская городская клиническая больница ДЗМ», г. Москва.

Молекулярно-генетический анализ проводился в ФГБНУ «МГНЦ им. академика Н.П. Бочкова» г. Москва и частных медицинских лабораториях по месту жительства пациентов.

\section{Результаты.}

Паџиент 1. 5,5 лет. При рождении рост 52 см, вес 3130 грамм, двусторонняя дисплазия тазобедренных суставов, деформация грудной клетки. С первых месяцев жизни - низкие темпы роста, дефицит веса, задержка моторного развития, особенности фенотипа (клювовидный нос, низкопосаженные ушные раковины, большие шаровидные глаза, микрогнатия). Дифференциальный диагноз проводился с синдромами Секкеля, Элерса-Данло тип 6. В 3,5 года рост 86 см (SDS -2,99), вес 9 кг. SDS ИМТ -4,34. Гормональный профиль без особенностей. В 4 года рост 86 см SDS -3,7; вес 9 кг. SDS веса -6,3 SDS ИМТ -4,3. Соматомедин С 115 нг/мл. Учитывая прогрессирующую задержку роста, была инициирована пробная терапия гормоном роста (6 месяцев) - без эффекта.

В 5 лет проведено полное секвенирование экзома: во 2 экзоне гена LMNA выявлена патогенная гетерозиготная мутация c.412G $>$ A (p.(Glu138Lys)), описанная при Атипичном прогероидном синдроме.

Пациентка 2. 2,10 лет. При рождении вес 3200 г, длина тела 49 см. С первого месяца жизни изменение кожных покровов, плотные отеки нижней половины туловища, надлобковой области и нижних конечностей. Заподозрен диагноз Склерема новорожденных. С 1 до 6 месяцев жизни получала терапию дексаметазоном, в дальнейшем диагноз был исключен. 
С 3-4 месяцев - прогрессирующее снижение темпов роста, отсутствие адекватного набора веса. После года тотальное выпадение волос на голове и бровей, формирование контрактур коленных и голеностопных суставов. Фенотипически заподозрен диагноз Прогерия Хадчинсона-Гилфорда. В 2,5 г. проведено полное секвенирование экзома, в 11 экзоне гена LMNA выявлена гетерозиготная сплайсинг-мутация с.1824C>T, характерная для прогерии Хадчинсона-Гилфорда. В 2,10 мес. учитывая высокий риск раннего развития жизнеугрожающих осложнений с высоким риском развития инфаркта или инсульта в детском возрасте по жизненным показаниям инициирована терапия ингибитором фарнезилтрансферазы Лонафарниб (Зокинви).

Пациент 3. 5 лет. При рождении масса 2800 грамм, рост 50 см. При рождении дисплазия тазобедренных суставов, с первого полугодия низкие темпы роста, прогрессирующий дефицит веса. C 3-4 лет - периодически рвота. Наблюдался гастроэнтерологом с диагнозом Целиакия с соблюдением аглютеновой диеты. В 5 лет - рост 100 см SDS -2,35 вес 11 кг SDS ИМТ-5,94. Учитывая особенности фенотипа, заподозрена Прогерия Хатчинсона-Гилфорда. Диагноз подтвержден данными генетического исследования, что явилось основанием для назначения препарата Лонафарниб.

Заключение: несмотря на характерные фенотипические особенности и классическое течение заболевания, во всех случаях обращает внимание относительно поздняя верификация диагноза, что может быть обусловлено крайней редкостью данной патологии. Специфические методы терапии прогерии и атипичного прогероидного синдрома в настоящее время не разработаны, однако согласно опубликованным клиническим данным назначение ингибитора фарнезилтрансферазы (Лонафарниб) снижает риск сердечно-сосудистых осложнений и увеличивает продолжительность жизни пациентов. Таким образом, ранняя генетическая верификация необходима для проведения дифференциальной диагностики с другими формами синдромальной низкорослости и выбора оптимальной тактики ведения пациентов.

Ключевые слова: прогерия, атипичный прогероидный синдром, синдромальная задержка роста, LMNA 